\title{
Application of "Tissueoid Cell Culture System" Using a Silicate Fiber Scaffold for Cancer Research
}

\author{
Shoko Murakamia,b Ken-ichi Mukaisho ${ }^{a}$ Takuya Iwasac Masaaki Kawabe ${ }^{c}$ \\ Saori Yoshida ${ }^{a}$ Naoko Taniura $^{a}$ Takahisa Nakayama $^{a}$ Masaharu Noi ${ }^{a}$ b \\ Gaku Yamamoto $^{\text {b }}$ Hiroyuki Sugihara ${ }^{a}$ \\ ${ }^{a}$ Division of Molecular and Diagnostic Pathology, Department of Pathology, Shiga University of Medical Science, \\ Otsu, Japan; bepartment of Oral and Maxillofacial Surgery, Shiga University of Medical Science, Otsu, Japan; \\ 'Central Research Laboratory, Japan Vilene Company, Ltd, Koga, Japan
}

\section{Keywords}

Tissueoid · Three-dimensional culture system · Cell culture · Silica fiber · Cancer research

\begin{abstract}
Background: We developed a 3-dimensional (3D) culture system using a high-purity silica fiber scaffold of unwoven sheets called Cellbed ${ }^{\mathrm{TM}}$. Methods: We used adherent colon and esophagogastric junction adenocarcinoma cells, tongue squamous cell carcinoma (SqCC) cells, and nonadherent gastric cancer cells. These cells were subjected to staining with various substances and observed by electron microscopy. To evaluate the effects of extracellular matrix in carcinoma tissues, SqCC cells were cultured in Cellbed coated with collagens I, III, and IV. Results: Especially well-differentiated carcinoma cells cultured in this 3D system showed their own unique characteristics: luminal formation in adenocarcinoma cells and cell stratification and keratinization in SqCC cells. Scanning electron microscopy revealed the proliferation of cancer cells with cytoplasm entwined in Cellbed. Intercellular desmosomes in squamous epithelia were detected by transmission electron microscopy of vertical cross sec-
\end{abstract}

karger@karger.com www.karger.com/pat

Karger $\frac{1}{6}$

GOPEN ACCESS
(C) 2020 The Author(s)

Published by S. Karger AG, Basel

This article is licensed under the Creative Commons Attribution 4.0 International License (CC BY) (http://www.karger.com/Services/ OpenAccessLicense). Usage, derivative works and distribution are permitted provided that proper credit is given to the author and the original publisher. tions. SqCC cells cultured in Cellbed coated with collagen IV showed enhanced invasive and proliferative abilities. Conclusion: Because the morphology of cancer cells cultured in this $3 \mathrm{D}$ culture system is similar to that in living organisms, we called the system a "tissueoid cell culture system." Coating with collagen IV enables the modification of cell-matrix interactions as well as recapitulation of the in vivo microenvironment.

(C) 2020 The Author(s)

Published by S. Karger AG, Basel

\section{Introduction}

Conventional 2-dimensional (2D) monolayer cell culture reportedly does not recapitulate the in vivo cancer microenvironment where cancer cells grow in a 3D manner [1]. 3D in vitro cell culturing is an innovative approach in cancer research to bridge the gap between conventional $2 \mathrm{D}$ culture and in vivo tumors [2]. Thus, many tools are now available for the development of in vitro 3D cultures [3]. The presence of a scaffold is important for the growth of cancer cells and the morphogenesis of a 3D structure [3]. Various biomimetic materials including ex- 
Table 1. Characteristics of the cell lines and media

\begin{tabular}{|c|c|c|c|c|}
\hline Cell line & Original region & Histologic type & Differentiation & Medium \\
\hline OE-19 & gastroesophageal junction & adenocarcinoma & moderate & $\mathrm{RPMI}+10 \% \mathrm{FBS}+1 \% \mathrm{ABAM}$ \\
\hline $\begin{array}{l}\text { HSC-3 } \\
\text { HSC-4 } \\
\text { SCC-15 }\end{array}$ & tongue & squamous cell carcinoma & $\begin{array}{l}\text { poor } \\
\text { well-differentiated } \\
\text { well-differentiated }\end{array}$ & $\begin{array}{l}\text { DMEM + 10\% FBS + 1\% ABAM } \\
\text { DMEM/Ham's F- } 12+10 \% \text { FBS + 1\% } \\
\text { ABAM + } 0.4 \mu \mathrm{g} / \mu \mathrm{L} \text { hydrocortisone }\end{array}$ \\
\hline $\begin{array}{l}\text { SNU-1 } \\
\text { KATOIII }\end{array}$ & stomach & adenocarcinoma & $\begin{array}{l}\text { signet-ring cell } \\
\text { carcinoma }\end{array}$ & $\mathrm{RPMI}+10 \% \mathrm{FBS}+1 \% \mathrm{ABAM}$ \\
\hline
\end{tabular}

tracellular matrix (ECM) as well as synthetic materials are currently used as scaffolds in 3D culture systems [2,4-7]. In this study, a 3D culture carrier known as Cellbed ${ }^{\mathrm{TM}}$ (Japan Viline Co., Tokyo, Japan) was used as a scaffold for cancer cell culture. Cellbed is a high-purity silica glass fiber aggregate sheet which has ultrafine and continuous porosity (Fig. 1a) [8]. Its lattice-like structure is thought to resemble the loose connective tissue in living organisms (Fig. 1b) [8, 9]. It is difficult to observe cells during culture as Cellbed is opaque in the culture medium; however, cells can be visualized using a mounting medium with a refractive index of 1.46 , similar to that of silica fiber, after staining with various substances [8]. Furthermore, horizontal and vertical cross-sectional specimens can be prepared from fixed Cellbed sections after culturing the cells in this system, thereby clarifying their behavior in 3D environments $[8,9]$. Using this system, we cultured squamous cell carcinoma (SqCC) cells and other adherent adenocarcinoma cells as well as nonadherent gastric cancer cells. We performed morphological assessments using scanning electron microscopy (SEM) and transmission electron microscopy (TEM) as well as hematoxylin-eosin (HE) staining, immunostaining, and fluorescence immunostaining.

To reproduce the microenvironment found within living organisms in a $3 \mathrm{D}$ system, we focused not only on the layered framework of fibers found within loose connective tissue in vivo, but also on the presence of an abundant ECM between the fibers. The ECM not only serves as the scaffold upon which tissues are organized, but also provides critical biochemical and biomechanical cues that direct cell growth, survival, migration, and differentiation and modulate vascular development and immune function [10]. The purity and structure of Cellbed allows a matrix to be added. A previous study reported the effects of using laminin, collagen I, and fibronectin as matrices with Cellbed $[11,12]$. In this study, we coated Cellbed with several collagens to clarify the roles of ECM.

\section{Materials and Methods}

\section{Cancer Cells and Cell Culture}

We used various adherent cancer cells including the gastroesophageal junction adenocarcinoma (OE-19), colorectal adenocarcinoma (DLD-1), and tongue SqCC (HSC-3, HSC-4, and SCC15) cell lines. Gastric cancer cell lines (SNU-1 and KATOIII) were also used as nonadherent lines. The characteristics of and suitable culture conditions for these cells are summarized in Table 1 [1319]. Both $2 \mathrm{D}$ and $3 \mathrm{D}$ cultures were incubated at $37^{\circ} \mathrm{C}$ and $5 \% \mathrm{CO}_{2}$. Initially, the cells were seeded in a $19-\mathrm{mm}$ Cellbed in a 12 -well plate $\left(4 \times 10^{4}\right.$ cells $\left./ \mathrm{mL}\right)$ for $3 \mathrm{D}$ culture. Seven days later, cells were transferred to a larger container or flask with an adequate volume of medium. To prevent pooling of the medium consumed by cancer cells within the center of the Cellbed, it was necessary to shake the container even on days when the cell culture medium was not changed. This was done to prevent ischemia and subsequent necrotic death of the cells.

\section{Various Stainings}

HE staining of cells in the Cellbed was performed in accordance with a previously reported method [8]. Immunohistochemical staining was carried out using the Discovery XT Automated IHC Stainer with a Ventana DABMap Detection Kit (Ventana Medical System, AZ, USA). The primary antibodies were visualized by the addition of substrate and chromogen, 3,3'-diaminobenzidine (DAB), with positive cells staining brown. All antigens were retrieved by heating. Information regarding all antibodies is listed in Table 2. Fluorescence immunostaining was conducted in Cellbed for approximately 4 weeks, in accordance with a previously reported method [8]. The primary antibodies used are listed in Table 2.

\section{Scanning Electron Microscopy}

HSC-4 cells seeded on 19-mm-diameter Cellbed for 2 weeks were used for SEM. Samples were prepared with a Tokai Electron Microscope Analysis (Nagoya, Japan). The samples were fixed at 

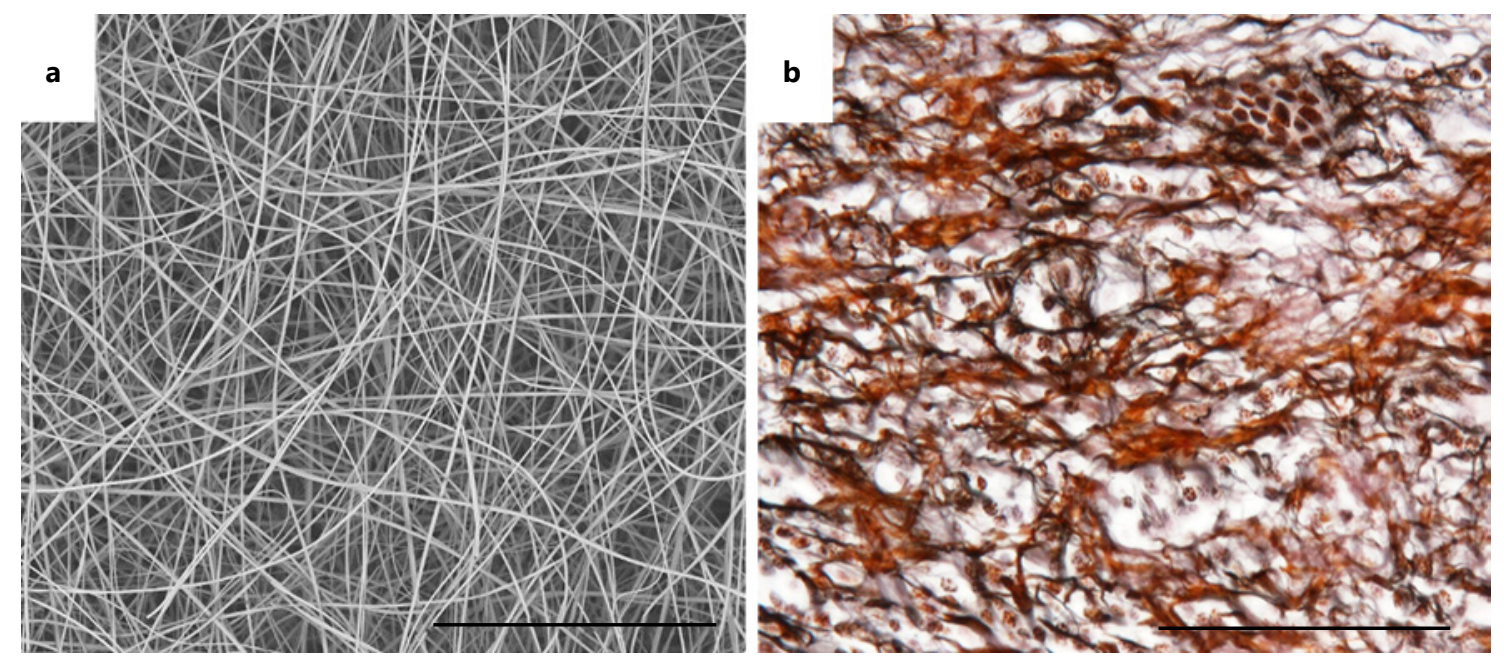

Fig. 1. Cellbed structure resembling loose connective tissue. a Cellbed is a fiber aggregate produced by the amalgamation of continuously formed silica fibers in a sheet-like shape. Scale bar, $100 \mu \mathrm{m}$. The average thickness of the silica fibers is about $1 \mu \mathrm{m}$. b Silver staining of normal human tongue tissue. Scale bar, $100 \mu \mathrm{m}$.

$4{ }^{\circ} \mathrm{C}$ for $1 \mathrm{~h}$ in $1 \%$ tannic acid in $0.1 \mathrm{M}$ cacodylate buffer, $\mathrm{pH} 7.4$, and then subjected to 4 washes, lasting $30 \mathrm{~min}$ each, in $0.1 \mathrm{M}$ cacodylate buffer; they were then postfixed in $2 \%$ osmium tetraoxide in $0.1 \mathrm{M}$ cacodylate buffer at $4^{\circ} \mathrm{C}$. Next, the samples were dehydrated using alcohol. The alcohol was replaced with tert-butyl alcohol at room temperature, and the frozen samples were vacuum-dried. After drying, the samples were coated with osmium (30 nm) using an osmium plasma coater (NL-OPC80A; Nippon Laser \& Electronics Laboratory, Nagoya, Japan), and viewed using a scanning electron microscope (JSM-7500F; Jeol, Tokyo, Japan).

Transmission Electron Microscopy

SCC-15 cells were seeded on a 19-mm-diameter collagen-IVcoated Cellbed and cultured for approximately 4 weeks. Sample preparation and imaging were performed by Tokai Electron Microscopy, in accordance with a previously reported method [8].

\section{Evaluation of the Effects of Collagen I, III, and IV Coating}

Collagen Coating

Five hundred microliters of $10 \times$ diluted Cellmatrix I and Cellmatrix IV (Nitta Gelatin, Osaka, Japan) in dilute hydrochloric acid ( $\mathrm{pH} 3.0$ ), and $500 \mu \mathrm{L}$ of $300 \times$ diluted collagen type III ( $3 \mathrm{mg} /$ $\mathrm{mL}$ ) (Nippi, Tokyo, Japan) in dilute acetic acid (5 mM) were added to each well of Cellbed in a 12 -well plate. The plate was protected from light and immersed overnight at $4{ }^{\circ} \mathrm{C}$. The solution was aspirated, after which the plate was air-dried on a clean bench for $30 \mathrm{~min}$, followed by 2 washes with the medium used for the cell lines.

\section{Serial Dilution Experiment Using Collagen IV}

Five hundred microliters of $2 \times, 5 \times, 10 \times$, and $100 \times$ diluted Cellmatrix IV in dilute hydrochloric acid ( $\mathrm{pH}$ 3.0) were added to each well of Cellbed in a 12-well plate. The subsequent process for the preparation was as described above.

Tissueoid Cell Culture Using Silicate Fiber
Table 2. First antibodies

\begin{tabular}{|c|c|c|c|c|}
\hline & Isotype & Clone & $\begin{array}{l}\text { Dilution } \\
\text { rate }\end{array}$ & Supplier \\
\hline \multicolumn{5}{|c|}{ Immunohistochemistry } \\
\hline MUCl & mouse & Ma695 & $1 / 100$ & Novocastra \\
\hline CK17 & mouse & & $1 / 40$ & Agilent Dako \\
\hline CK (AE1/AE3) & mouse & AE1/AE3 & diluted & Agilent Dako \\
\hline Ki67 & rabbit & Sp6 & $1 / 100$ & $\begin{array}{l}\text { Abcam } \\
\text { Cambridge }\end{array}$ \\
\hline \multicolumn{5}{|c|}{ Immunofluorescence } \\
\hline Ezrin & rabbit & & $1 / 200$ & Cell Signaling \\
\hline Cortactin & rabbit & EP1922Y & $1 / 1,000$ & $\begin{array}{l}\text { Abcam } \\
\text { Cambridge }\end{array}$ \\
\hline
\end{tabular}

Measurement of Depth of Tongue Cancer Cell Invasion

After 2 weeks of 3D culture, vertical paraffin sections were stained with HE, the depth of invasion was measured using a light microscope at $\times 400$ magnification and $\times 40$ focus, and the average was calculated. The depths of invasion in collagen I-, III-, and IVcoated and uncoated Cellbeds were compared.

\section{Ki67 Index}

A light microscope at $\times 200$ magnification and $\times 10$ focus was used to determine the rate of Ki67 positivity. Immunostaining with Ki67 was performed using a sectioned sample of the vertical section of the collagen I-, III-, and IV-coated and uncoated Cellbeds after 2 weeks of $3 \mathrm{D}$ culture.

\section{Statistical Analysis}

Student's $t$ test was used for statistical analysis to evaluate the effects of collagens I, III, and IV on invasion depth and proliferative ability.

Pathobiology 2020;87:291-301 

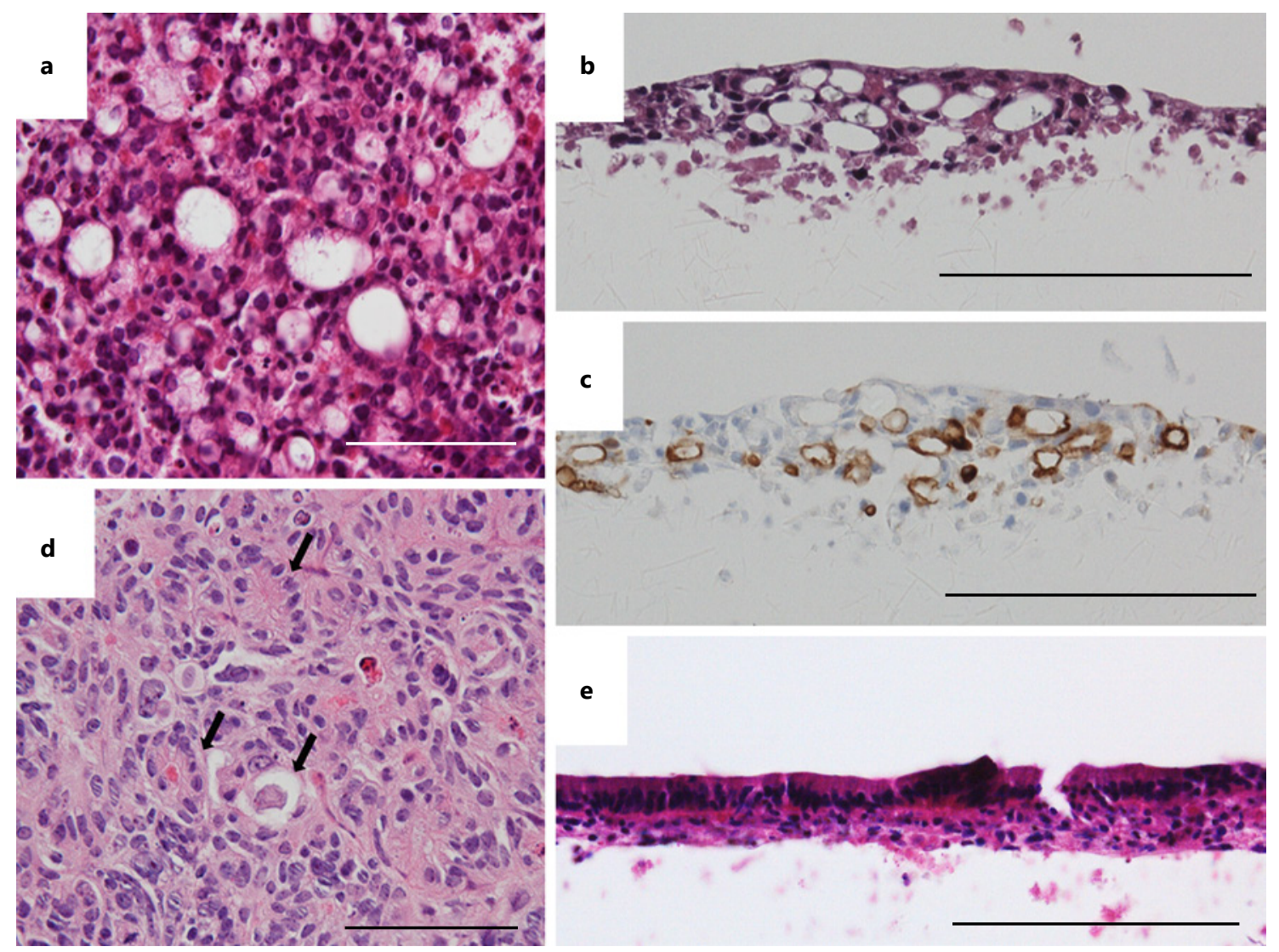

Fig. 2. Adenocarcinoma cells (adherent cells). a A horizontal section of OE-19 cells cultured for 4 weeks. Scale bar, $100 \mu \mathrm{m}$. HE. A luminal structure was detected in the gland. b A vertical section from the 4-week culture. HE. c MUC1 was positive on the luminal surface. Scale bar, $200 \mu \mathrm{m}$. d A horizontal section of DLD-1 cells cultured for 3 weeks. Lumina-like structures of the glandular cavity were visible (arrow). Scale bar, $100 \mu$ m. HE. e A vertical section of DLD-1 cells cultured for 4 weeks. Scale bar, $200 \mu \mathrm{m}$. HE. We partly detected that columnar cells exhibited polarity and were regularly aligned on the Cellbed surface.

\section{Results}

\section{Observation of Adherent Adenocarcinoma Cells}

Clear ductal luminal formations were observed in horizontal and vertical cross sections of 3D cultures of OE-19 cells (Fig. 2a, b). Additionally, immunostaining was successfully performed using the first antibody of MUC1 (Fig. 2c). In experiments with colon cancer cell lines, luminal-like structures were observed in horizontal sections of 3D cultures of DLD-1 cells (Fig. 2d). In the vertical sections of 3D cultures, DLD-1 cells partly exhibited polarity and were regularly aligned on the surface of Cellbed (Fig. 2e).

\section{Observation of Tongue SqCC Cells}

Abnormal keratinization and cell stratification, which are characteristics of well-differentiated SqCC cells, were observed in horizontal and vertical cross-sections of HSC-4 and SCC15 cells grown in 3D culture (Fig. 3a-c). Staining positivity was confirmed upon immunostaining using CK17 (Fig. 3d) and fluorescence immunostaining using ezrin (green) and cortactin (red; Fig. 3e-h). HSC-4 scanning electron micrographs showed that cancer cells were present among the Cellbed fibers with cytoplasm (Fig. 4a, b). Desmosomes were observed between cells by TEM of vertical cross-sections of SCC-15 cells grown for 4 weeks in 3D culture (Fig. 4c, d).

\section{Morphological Observation of Nonadherent Cells}

SNU-1 and KATOIII cells proliferated in the 3D culture system (Fig. 5a, b). These cancer cells were partly clustered, but no luminal structure was detected. Immunostaining experiments were successfully performed using formaldehyde-fixed paraffin-embedded sections of 

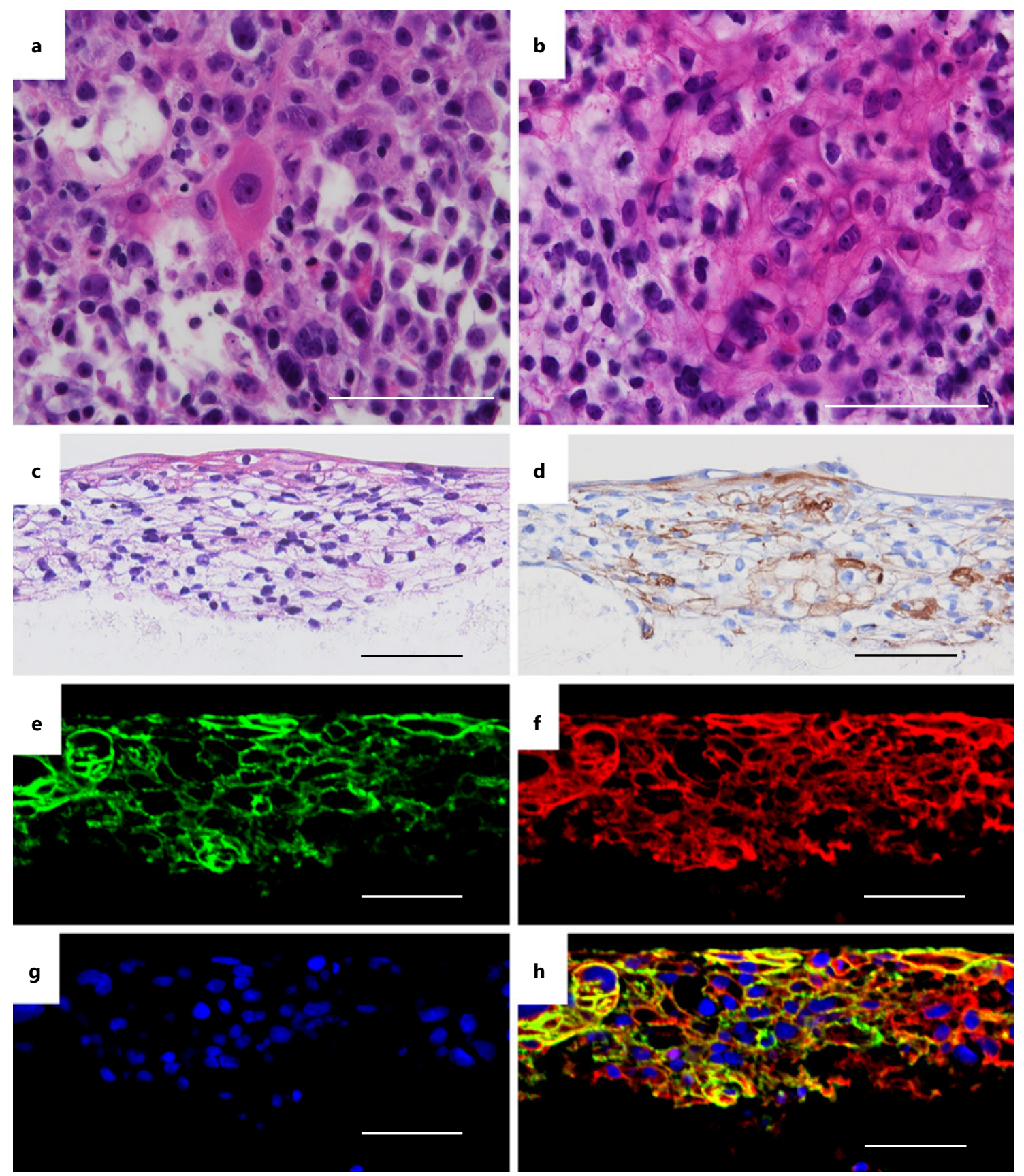

Fig. 3. Squamous cell carcinoma cells. Abnormal keratinization in HSC-4 cells (a) and SCC-15 cells (b) in 3D culture. c Three-week culture of HSC-4 cells in vertical cross-sections. A layered structure and surface-lying differentiated cells were observed. d CK17-positive cells were detected. e-h Cells cultured for 4 weeks. Fluorescence immunostaining of vertical sections (DAPI, blue; ezrin, green; cortactin, red). Scale bar, $100 \mu \mathrm{m}$.

growing cells in Cellbed (Fig. 5c, d). Most SNU-1 cells were positive for Ki67 (nuclear staining; Fig. 5c) and all KATOIII cells were positive for CK (AE1/AE3; membranous and cytoplasmic staining; Fig. 5d).

Tissueoid Cell Culture Using Silicate Fiber

\section{Collagen IV Coating Increases Invasion Depth}

We evaluated the invasion depth of cancer cells in the vertical section of Cellbed, the results of which are shown in Figure 6. We had reported previously that cell projec-

Pathobiology 2020;87:291-301 DOI: $10.1159 / 000509133$ 

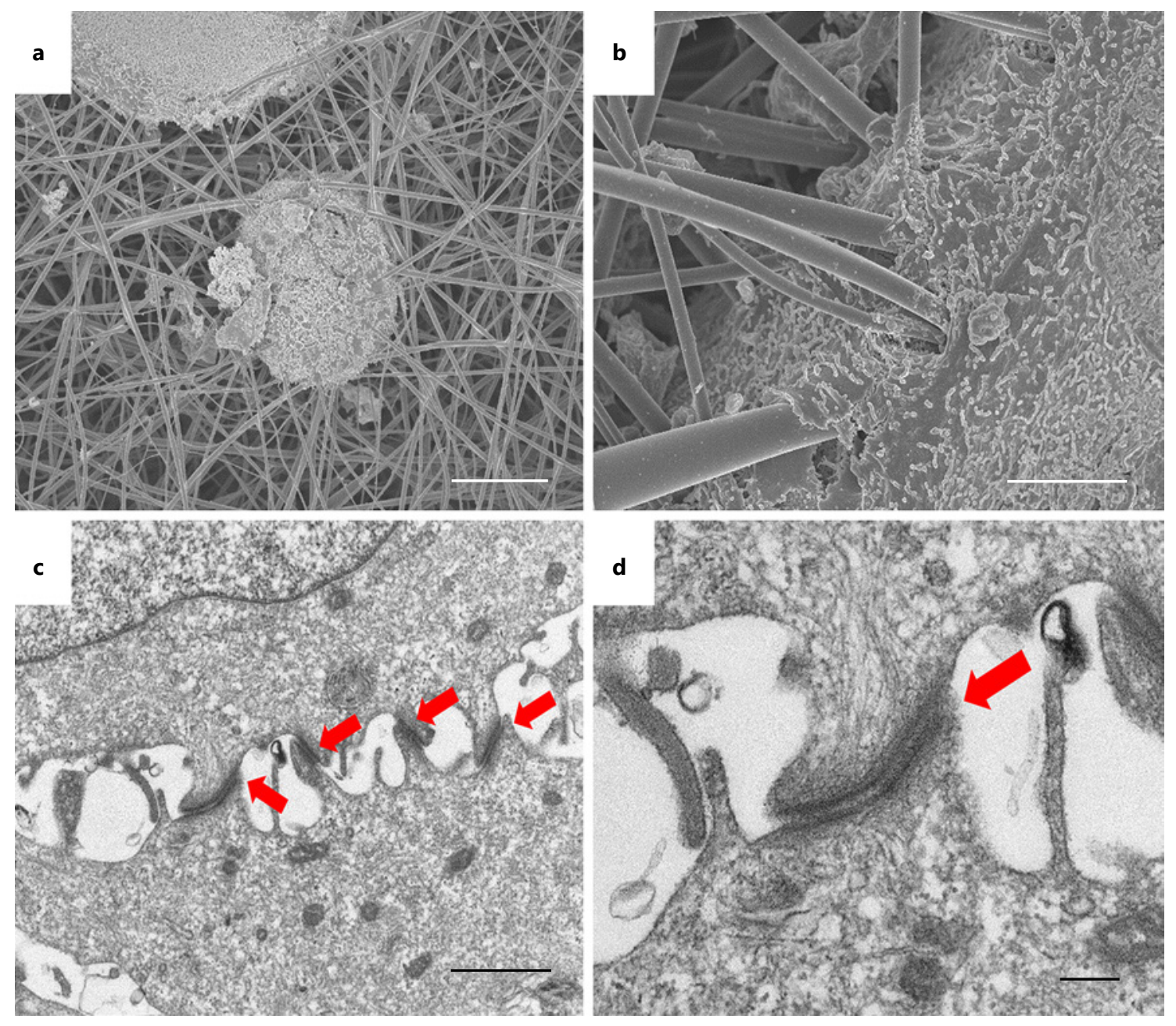

Fig. 4. Electron microscopy image of 3D culture of squamous cell carcinoma cells. Scanning electron micrograph of HSC- 4 cells cultured for 2 weeks. a A proliferating cell entangled in Cellbed fibers. Scale bar, $20 \mu \mathrm{m}$. b Confirmation of cellular extension into Cellbed. Scale bar, $5 \mu \mathrm{m}$. c, d Transmission electron microscopy image of SCC15 cells cultured for 4 weeks. d A magnified image of (c). Desmosomes were observed even in the vertical section (arrows) Scale bar, $1 \mu \mathrm{m}$.

tions within HSC- 3 and HSC- 4 cells cultured in a Cellbed could be readily detected, in contrast to the results found using cells cultured in a $2 \mathrm{D}$ condition [8]. These cytological changes were also observed in this study, and we further show that HSC-3 and HSC-4 cells display similar cytological and histological characteristics regardless of the type of collagen (Fig. 6a). However, such invasion was significantly deeper for HSC-3 and HSC-4 cells in the collagen IV-coated group than in the uncoated group (HSC3: $p<0.01$, HSC-4: $p<0.05$; Fig. 6b, c).

Having found significant differences in the invasion depth on comparison of the uncoated group and the col-
lagen-IV coated group, we evaluated the invasion depth of cancer cells in the collagen-IV coated group by means of serial dilution experiments. The invasion depth was significantly deeper for HSC-3 cells in the collagen IVcoated group, at all dilutions $(\times 2, \times 5, \times 10, \times 100)$, than for those in the uncoated group ( $p<0.01$; Fig. $6 \mathrm{~d})$. The invasion depth was significantly deeper for HSC-4 cells using collagen IV, coated at $\times 10$ dilution, than for those in the uncoated group ( $p<0.05$; Fig. $6 \mathrm{e}$ ). From these results, $\times 10$ dilution of collagen-IV is the most suitable environment for the invasion of SqCC cells. 


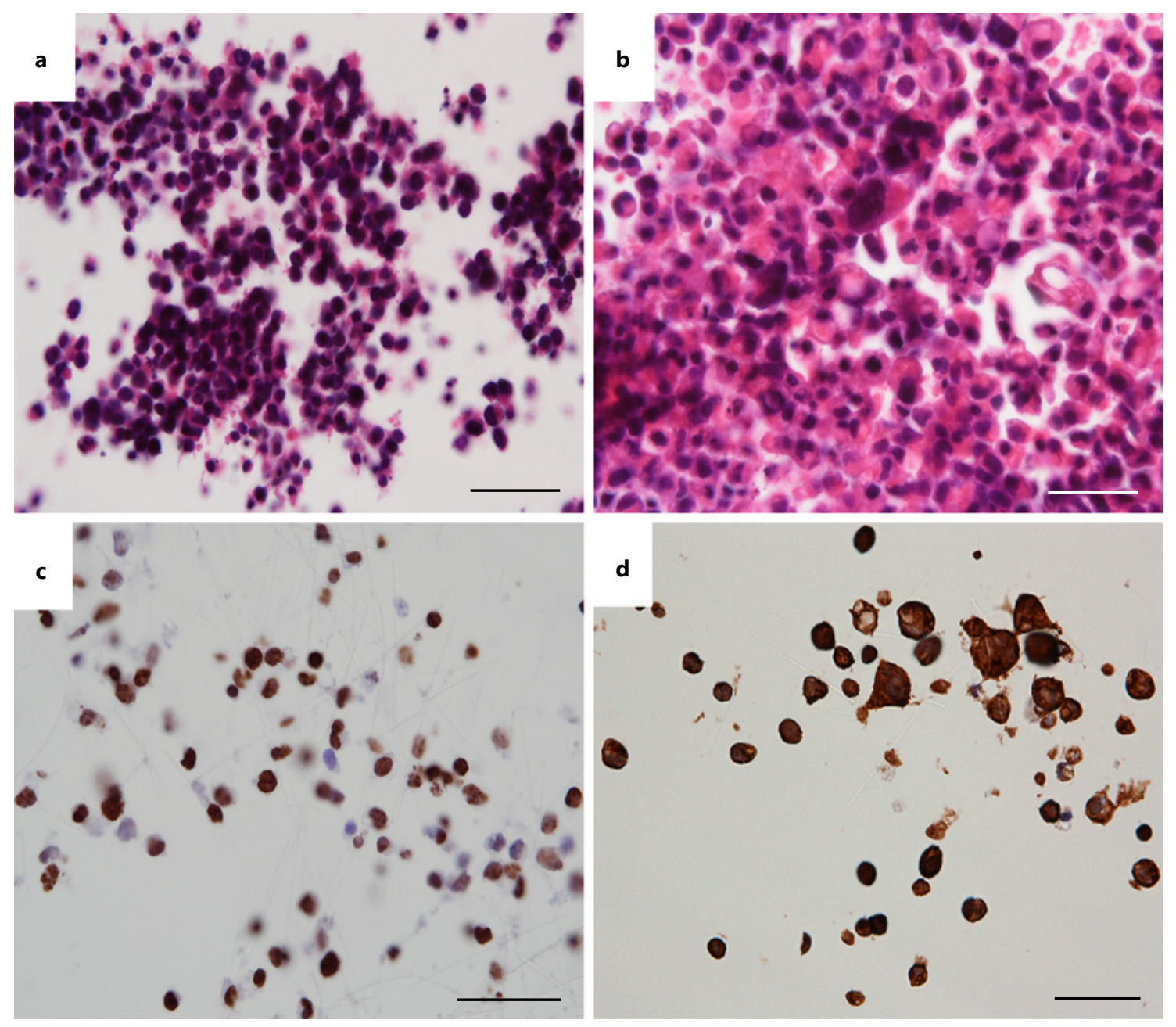

Fig. 5. Adenocarcinoma cells (nonadherent cells), a SNU-1 cells cultured for 3 weeks. Scale bar, $50 \mu \mathrm{m}$. HE. b KATOIII cells cultured for 3 weeks. Scale bar, $50 \mu \mathrm{m}$. HE. SNU-1 and KATOIII cells partly clustered, but no obvious luminal structure was detected. c Ki67 immunostaining of SNU-1 cells cultured for 3 weeks. Scale bar, $50 \mu \mathrm{m}$. Most SNU-1 cells were positive for Ki67. d CK (AE1/AE3) immunostaining of KATOIII cells cultured for 3 weeks. Scale bar, $50 \mu \mathrm{m}$. All KATOIII cells were positive for CK (AE1/AE3).

\section{Effects of Collagen I, III, and IV on Proliferative} Ability

The Ki67 index was significantly higher in HSC-3 cells in the collagen I-, III-, and IV-coated group than those in the uncoated group (collagen I: $p<0.01$, collagen III: $p<$ 0.01 , collagen IV: $p<0.05$; Fig. 7a). The Ki67 index was significantly higher in HSC-4 cells in the collagen III- and IV-coated group than those in the uncoated group (collagen III: $p<0.05$, collagen IV: $p<0.01$; Fig. 7b). Figure $7 \mathrm{c}$ shows the representative figures of the immunostaining of Ki67 in each group.

Tissueoid Cell Culture Using Silicate Fiber

\section{Discussion}

The morphology of 3D cultured cells using a Cellbed scaffold is very similar to that in cancer tissues. We termed this system "tissueoid cell culture system." We were able to assess the significance of the in vivo microenvironment by coating Cellbed with various collagen fibers. We proved that collagen IV coating enhanced the invasive and proliferative abilities of SqCC cells.

"Tissueoid" is a recently coined term. It was initially used to refer to an artificial tissue using a decellularized part of living tissue [20]. We slightly modified it and used 


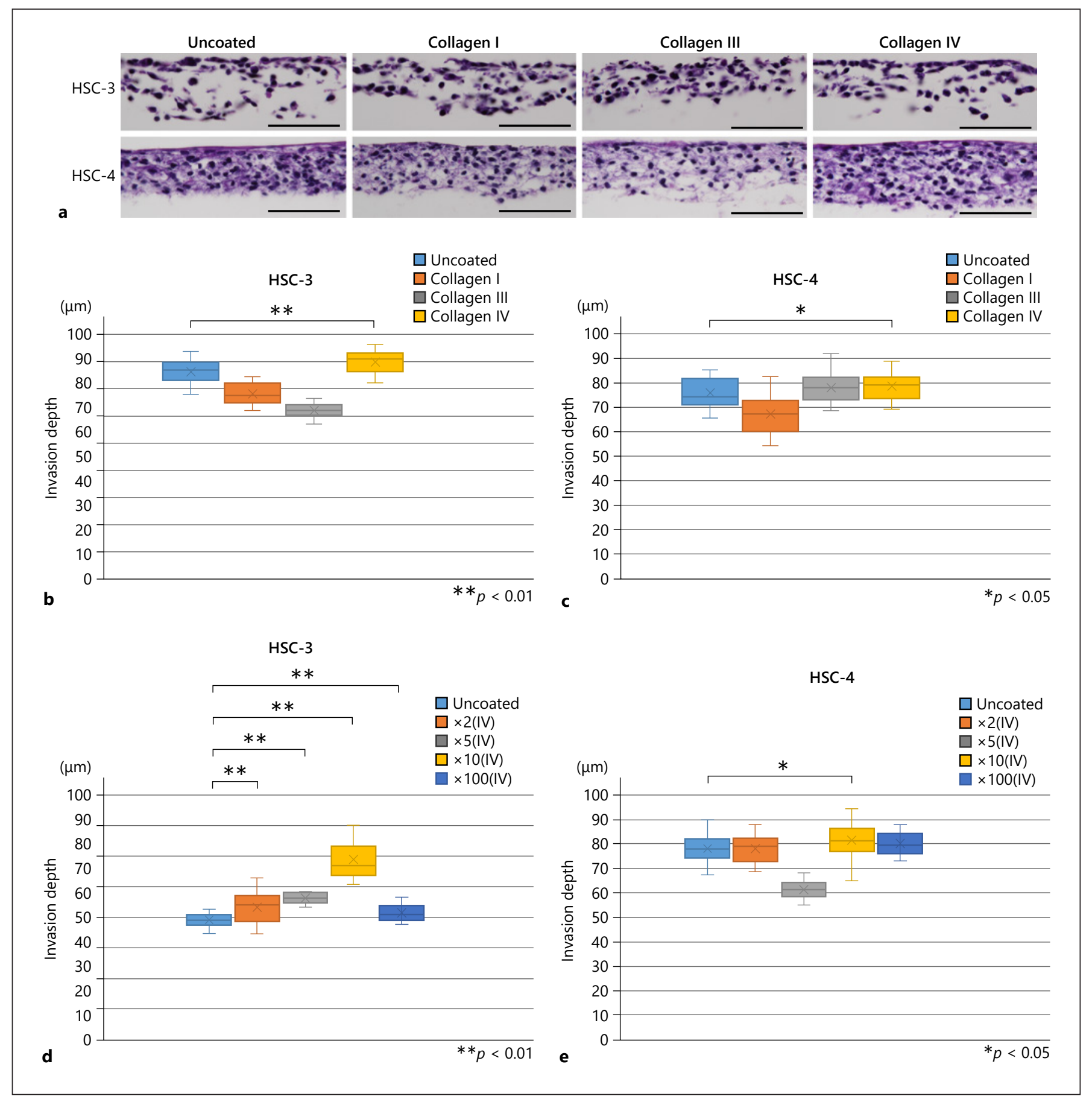

Fig. 6. Effects of collagen I, III, and IV coating on invasion depth. a HSC-3 and HSC-4 cells display similar cytological and histological characteristics regardless of the type of collagen. Scale bar, 200 $\mu \mathrm{m}$. b, c The invasion depth was significantly deeper for the collagen IV-coated HSC-3 and HSC-4 cells than for the uncoated group $\left(* p<0.05,{ }^{* *} p<0.01\right)$. d The invasion depth was signifi-

cantly deeper for HSC-3 cells in the collagen IV-coated group, at all dilutions $(\times 2, \times 5, \times 10, \times 100)$, than for those in the uncoated group $(p<0.01)$. e The invasion depth was significantly deeper for HSC- 4 cells using collagen IV, coated at $\times 10$ dilution, than for those in the uncoated group $(p<0.05)$. 


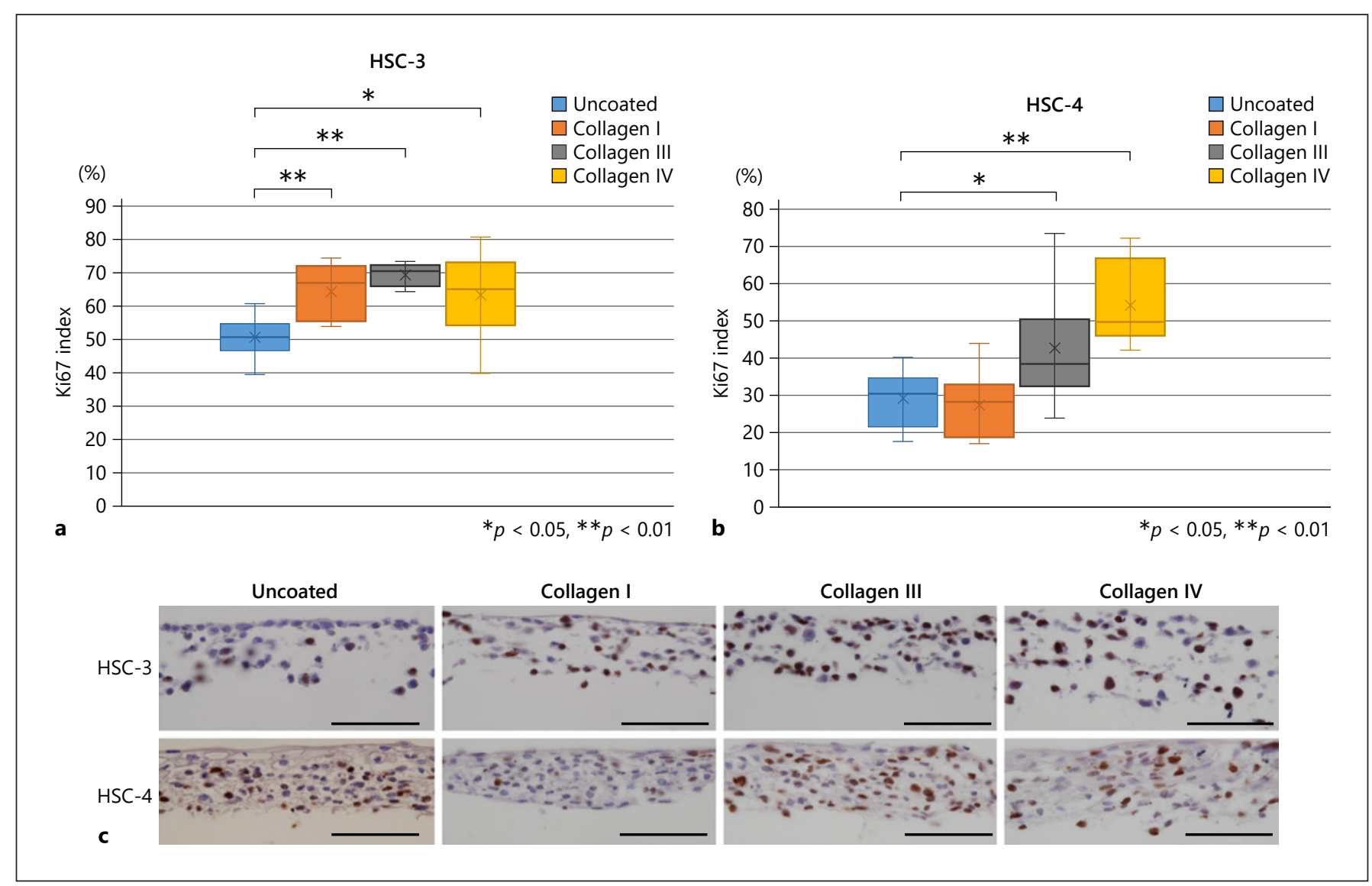

Fig. 7. Effects of collagen I, III, and IV coating on cell proliferation. a HSC-3, (b) HSC-4, (c) Ki67 immunostaining. Scale bar, $200 \mu \mathrm{m}$. a The Ki67 index was significantly higher in HSC-3 cells in the collagen I-, III-, and IVcoated group than those in the uncoated group. b The Ki67 index was significantly higher in HSC-4 cells in the collagen III- and collagen IV-coated group than those in the uncoated group $\left(* p<0.05,{ }^{* *} p<0.01\right)$.

the term "tissueoid cell culture system" to refer to our 3D cell culture system. The tissueoid cell culture system has several advantages over other 3D cell culture approaches, such as Matrigel coating and spheroid cultures for the following reasons [21, 22]: (1) The procedures undertaken for the culture system are very simple; (2) as the scaffold resists heat and organic solvents such as xylene or alcohol, cultured cells can be directly used for various types of staining; (3) pure cultured cells can be used for various experiments [8]; and (4) we can coat ECM on the silicate fibers of Cellbed.

One of the most important factors in $3 \mathrm{D}$ cultures is the scaffold, which serves as an ECM substrate for cell growth and the formation of in vivo 3D structures [3]. We were able to carry out the $3 \mathrm{D}$ culture of all of the cancer cells applied to the tissueoid cell culture system. Because the cells can change morphology into a spindle shape and move freely in a cavity through the pores formed by the silicate fiber aggregate, especially welldifferentiated cancer cells could express the histological characteristics of the cells at each primary site. For example, luminal formation, which is a characteristic of differentiated adenocarcinoma, was observed when OE-19 and DLD-1 cells were cultured. However, Cellbed is not unique in facilitating the luminal structure formation in adenocarcinoma cells. For example, the physiological breast bilayer was reproduced by formation of luminal structures in collagen gels [23], and adenocarcinoma cells form a luminal structure in $3 \mathrm{D}$ Matrigel [24]. However, Cellbed is a 3D culture carrier that supports the formation of the unique characteristics of each cancer cell. On the other hand, neither signet-ring cell carcinoma SNU1 nor KATOIII formed glandular structures. 
Cell stratification and abnormal keratinization, typical characteristics of well-differentiated SqCC, were observed when HSC- 4 and SCC- 15 cells were cultured. Furthermore, the presence of desmosomes in vertical sections of SCC-15 cell cultures was confirmed by TEM. In contrast, poorly differentiated SqCC HSC-3 cells did not form obvious stratification.

These results imply that the tissueoid cell culture system accurately recapitulates the 3D morphology of cancer cells in vivo.

Interactions and cross-talk between cancer cells and various stromal cells of tumor tissue might lead to the formation of a cancer-specific microenvironment in tumor invasion and metastasis [25]. Thus, some ECM plays an important role in cancer progression [26]. The ECM can be divided into 2 matrices: interstitial matrix (IM) and basement membrane (BM) [26]. IM makes up the main stroma and plays a major role in cell migration, cell adhesion, angiogenesis, tissue development, and repair. The BM is a well-structured membrane underlying epithelial and endothelial cells [27]. The IM is dominated by fibrillary-forming collagens such as collagen I, II, and III whereas the major components of the BM are networkforming collagens such as collagen IV [26]. Collagen II is the main collagen in cartilage, so we did not investigate it in this study. Collagens I and III are the most and secondmost abundant collagens in the IM, respectively, where they play key structural roles [28]. Apart from its structural role, collagen I possesses important growth factorbinding potential, and regulates cell homeostasis by binding to a variety of proteins [28]. The remodeling of the $\mathrm{BM}$ leads to a complex array of pro- and antitumor signals from degradation products [29]. Previous studies have reported that the rate of collagen I and III degradation is associated with patient survival in head and neck SqCC $[30,31]$. Collagen IV is usually found only in the $\mathrm{BM}$, but during pathogenesis, it is associated with organ or tumor fibrosis, accumulates in the tumor stroma, and plays an important role in the adhesion, migration, differentiation, and growth of cells [32]. Moreover, collagen IV is a potent and essential regulator of angiogenesis [3335]. Our results suggest that the ability of cancer cells to invade and proliferate was enhanced in microenvironments in which collagen IV was present.

ECM remodeling is primarily mediated by matrix metalloproteinases (MMPs), and MMP activity causes profound structural and mechanical changes in the developing ECM [36]. In this study, the invasion depths of HSC3 and HSC-4 cells were significantly less in the collagen I-coated group than in the uncoated group. This suggests that collagen I-coated fibers may resemble the in vivo tumor microenvironment before collagen I is decomposed by MMPs, while uncoated fibers may reproduce the in vivo tumor microenvironment after collagen I is degraded by MMPs. The detailed role of collagen III-coated fibers was not revealed in this study, but our results upon coating Cellbed with various collagen fibers enabled the assessment of the invasive and proliferative abilities of SqCC cells, which were not previously characterized by in vivo study. In the near future, we would like to evaluate the effects of cancer progression using other ECM proteins known to be crucial for cancer cell biology, such as fibronectin and/or laminin [37, 38].

Taking all the obtained findings together, we consider the tissueoid cell culture system to be applicable for studies of SqCC cells as well as adherent and nonadherent adenocarcinoma cells. We showed that collagen IV promoted invasion by SqCC cells. The addition of a matrix component such as collagens facilitated the recapitulation of in vivo SqCC cells. The tissueoid cell culture system could be considered a suitable experimental tool for use before in vivo studies.

\section{Acknowledgment}

We thank Professor Wataru Yasui of Hiroshima University for naming the $3 \mathrm{D}$ culture method using Cellbed in this research the "tissueoid cell culture system." Electron microscope images were provided by Tokai Electron Microscopy. We would like to express our gratitude to Shuji Kawamura (Tokai Electron Microscopy).

\section{Conflict of Interest Statement}

This research was done in collaboration with Japan Vilene Company, Ltd. The company provided Cellbed and information on Cellbed materials.

\section{Author Contributions}

S.M. performed almost all experiments and prepared the manuscript. K.M. planned the experiments and provided advice on the preparation of the manuscript. S.Y. and N.T. assisted in the experiment. T.I., M.K., T.N., M.N., G.Y., and H.S participated in discussions during the experiment and preparation of the manuscript and provided good advice. 


\section{References}

1 Branco da Cunha C, Klumpers DD, Koshy ST, Weaver JC, Chaudhuri O, Seruca R, et al. CD44 alternative splicing in gastric cancer cells is regulated by culture dimensionality and matrix stiffness. Biomaterials. 2016 Aug; 98:152-62.

2 Curtin C, Nolan JC, Conlon R, Deneweth L, Gallagher C, Tan YJ, et al. A physiologically relevant 3D collagen-based scaffold-neuroblastoma cell system exhibits chemosensitivity similar to orthotopic xenograft models. Acta Biomater. 2018 Apr;70:84-97.

3 Yamaguchi Y, Deng D, Sato Y, Hou YT, Watanabe R, Sasaki K, et al. Silicate fiberbased 3D cell culture system for anticancer drug screening. Anticancer Res. 2013 Dec; 33(12):5301-9.

4 Gonzalez Gonzalez M, Cichon I, ScislowskaCzarnecka A, Kolaczkowska E. Challenges in 3D culturing of neutrophils: assessment of cell viability. J Immunol Methods. 2018 Jun; 457:73-7.

5 Holliday DL, Brouilette KT, Markert A, Gordon LA, Jones JL. Novel multicellular organotypic models of normal and malignant breast: tools for dissecting the role of the microenvironment in breast cancer progression. Breast Cancer Res. 2009;11(1):R3.

6 Gurski LA, Jha AK, Zhang C, Jia X, FarachCarson MC. Hyaluronic acid-based hydrogels as $3 \mathrm{D}$ matrices for in vitro evaluation of chemotherapeutic drugs using poorly adherent prostate cancer cells. Biomaterials. 2009 Oct; 30(30):6076-85.

7 Horning JL, Sahoo SK, Vijayaraghavalu S, Dimitrijevic S, Vasir JK, Jain TK, et al. 3-D tumor model for in vitro evaluation of anticancer drugs. Mol Pharm. 2008 Sep-Oct;5(5): $849-62$.

8 Noi M, Mukaisho KI, Yoshida S, Murakami S, Koshinuma S, Adachi T, et al. ERK phosphorylation functions in invadopodia formation in tongue cancer cells in a novel silicate fibrebased 3D cell culture system. Int J Oral Sci. 2018 Oct;10(4):30.

9 Mukaisho K, Yoshida S, Noi M, Nakayama T, Iwasa T, Hattori T, et al. Morphology of Various Cancer Cells Using the Silicate Fiber Scaffold Cellbed in a Novel Three-Dimensional Cell Culture System. Gastroenterology. 2017;152(5 Suppl 1):S352-3.

10 Pickup MW, Mouw JK, Weaver VM. The extracellular matrix modulates the hallmarks of cancer. EMBO Rep. 2014 Dec;15(12):124353.

11 Mizutani T, Ishii T, Komizu Y, Iwasa T, Kawabe $\mathrm{M}$, Togawa $\mathrm{N}$, et al. Maintenance of viability and functional expression of cryopreserved human hepatocytes using silicate fiber-based three-dimentional scaffold. AATEX. 2017 Feb;22(1):101-6.
12 Iwasa T, Watanabe R, Sasaki K, Matsushita T, Akihiro Yamaguchi A, Kawabe M. A culture method of rat hepatocytes using the threedimensional cell culture scaffold "Cellbed" and its application for liver toxicity testing. AATEX. 2016 Dec;21(2):52-62.

13 Rockett JC, Larkin K, Darnton SJ, Morris AG, Matthews HR. Five newly established oesophageal carcinoma cell lines: phenotypic and immunological characterization. Br J Cancer. 1997;75(2):258-63.

14 Dexter DL, Barbosa JA, Calabresi P. N,N-dimethylformamide-induced alteration of cell culture characteristics and loss of tumorigenicity in cultured human colon carcinoma cells. Cancer Res. 1979 Mar;39(3):1020-5.

15 Matsui T, Ota T, Ueda Y, Tanino M, Odashima S. Isolation of a highly metastatic cell line to lymph node in human oral squamous cell carcinoma by orthotopic implantation in nude mice. Oral Oncol. 1998 Jul;34(4):253-6.

16 Momose F, Araida T, Negishi A, Ichijo H, Shioda S, Sasaki S. Variant sublines with different metastatic potentials selected in nude mice from human oral squamous cell carcinomas. J Oral Pathol Med. 1989 Aug;18(7):3915.

17 Rheinwald JG, Beckett MA. Tumorigenic keratinocyte lines requiring anchorage and fibroblast support cultured from human squamous cell carcinomas. Cancer Res. 1981 May; 41(5):1657-63.

18 Park JG, Frucht H, LaRocca RV, Bliss DP Jr, Kurita Y, Chen TR, et al. Characteristics of cell lines established from human gastric carcinoma. Cancer Res. 1990 May;50(9):277380.

19 Hattori Y, Odagiri H, Nakatani H, Miyagawa K, Naito K, Sakamoto H, et al. K-sam, an amplified gene in stomach cancer, is a member of the heparin-binding growth factor receptor genes. Proc Natl Acad Sci USA. 1990 Aug; 87(15):5983-7.

20 https://kaken.nii.ac.jp/ja/grant/KAKENHIPROJECT-16H03180/ in Japanese.

21 Bissell MJ, Radisky D. Putting tumours in context. Nat Rev Cancer. 2001 Oct;1(1):46-54.

22 Debnath J, Brugge JS. Modelling glandular epithelial cancers in three-dimensional cultures. Nat Rev Cancer. 2005 Sep;5(9):675-88.

23 Carter EP, Gopsill JA, Gomm JJ, Jones JL, Grose RP. A 3D in vitro model of the human breast duct: a method to unravel myoepithelial-luminal interactions in the progression of breast cancer. Breast Cancer Res. 2017 Apr; 19(1):50.

24 Libanje F, Raingeaud J, Luan R, Thomas Z, Zajac O, Veiga J, et al. ROCK2 inhibition triggers the collective invasion of colorectal adenocarcinomas. EMBO J. 2019 Jul;38(14): e99299.
25 Miyake M, Hori S, Morizawa Y, Tatsumi Y, Toritsuka M, Ohnishi S, et al. Collagen type IV alpha 1 (COL4A1) and collagen type XIII alpha 1 (COL13A1) produced in cancer cells promote tumor budding at the invasion front in human urothelial carcinoma of the bladder. Oncotarget. 2017 May;8(22):36099-114.

26 Nissen NI, Karsdal M, Willumsen N. Collagens and Cancer associated fibroblasts in the reactive stroma and its relation to Cancer biology. J Exp Clin Cancer Res. 2019 Mar;38(1): 115

27 Theocharis AD, Skandalis SS, Gialeli C, Karamanos NK. Extracellular matrix structure. Adv Drug Deliv Rev. 2016 Feb;97:4-27.

28 Kanematsu A, Marui A, Yamamoto S, Ozeki M, Hirano Y, Yamamoto M, et al. Type I collagen can function as a reservoir of basic fibroblast growth factor. J Control Release. 2004 Sep;99(2):281-92.

29 Tanjore H, Kalluri R. The role of type IV collagen and basement membranes in cancer progression and metastasis. Am J Pathol. 2006 Mar; 168(3):715-7.

30 Nurmenniemi S, Koivula MK, Nyberg P, Tervahartiala T, Sorsa T, Mattila PS, et al. Type I and III collagen degradation products in serum predict patient survival in head and neck squamous cell carcinoma. Oral Oncol. 2012 Feb;48(2):136-40.

31 Kumari K, Ghosh S, Patil S, Augustine D, Samudrala Venkatesiah S, Rao RS. Expression of type III collagen correlates with poor prognosis in oral squamous cell carcinoma. J Investig Clin Dent. 2017 Nov;8(4):e12253.

32 Kalluri R. Basement membranes: structure, assembly and role in tumour angiogenesis. Nat Rev Cancer. 2003 Jun;3(6):422-33.

33 Grant DS, Kibbey MC, Kinsella JL, Cid MC, Kleinman HK. The role of basement membrane in angiogenesis and tumor growth. Pathol Res Pract. 1994 Oct;190(9-10):854-63.

34 Haralabopoulos GC, Grant DS, Kleinman HK, Lelkes PI, Papaioannou SP, Maragoudakis ME. Inhibitors of basement membrane collagen synthesis prevent endothelial cell alignment in matrigel in vitro and angiogenesis in vivo. Lab Invest. 1994 Oct;71(4):57582.

35 Ingber D, Folkman J. Inhibition of angiogenesis through modulation of collagen metabolism. Lab Invest. 1988 Jul;59(1):44-51.

36 Wang K, Wu F, Seo BR, Fischbach C, Chen W, Hsu L, et al. Breast cancer cells alter the dynamics of stromal fibronectin-collagen interactions. Matrix Biol. 2017 Jul;60-61:86-95.

37 Erdogan B, Ao M, White LM, Means AL, Brewer BM, Yang L, et al. Cancer-associated fibroblasts promote directional cancer cell migration by aligning fibronectin. J Cell Biol. 2017 Nov;216(11):3799-816.

38 Engbring JA, Kleinman HK. The basement membrane matrix in malignancy. J Pathol. 2003 Jul;200(4):465-70.
Tissueoid Cell Culture Using Silicate Fiber
Pathobiology 2020;87:291-301

DOI: $10.1159 / 000509133$ 